\title{
Age differences in neural correlates of route encoding and route recognition
}

\author{
Olga Meulenbroek, ${ }^{\text {a }}$ Karl Magnus Petersson, ${ }^{\text {a,b }}$ Nicol Voermans, , ${ }^{\text {ac }}$ \\ Bernd Weber, ${ }^{\mathrm{d}}$ and Guillén Fernández ${ }^{\mathrm{a}, \mathrm{c}, *}$ \\ ${ }^{a}$ Cognitive Neurology and Memory Research Group, F.C. Donders Center for Cognitive Neuroimaging, University of Nijmegen, Nijmegen, The Netherlands \\ ${ }^{\mathrm{b}}$ Department of Clinical Neuroscience, Karolinska Institute, Stockholm, Sweden \\ ${ }^{\mathrm{c}}$ Department of Neurology, University Medical Centre Nijmegen, Nijmegen, The Netherlands \\ d Department of Epileptology, University of Bonn, Bonn, Germany
}

Received 23 October 2003; revised 27 February 2004; accepted 5 April 2004

Spatial memory deficits are core features of aging-related changes in cognitive abilities. The neural correlates of these deficits are largely unknown. In the present study, we investigated the neural underpinnings of age-related differences in spatial memory by functional MRI using a navigational memory task with route encoding and route recognition conditions. We investigated 20 healthy young $(18-29$ years old) and 20 healthy old adults (53-78 years old) in a random effects analysis. Old subjects showed slightly poorer performance than young subjects. Compared to the control condition, route encoding and route recognition showed activation of the dorsal and ventral visual processing streams and the frontal eye fields in both groups of subjects. Compared to old adults, young subjects showed during route encoding stronger activations in the dorsal and the ventral visual processing stream (supramarginal gyrus and posterior fusiform/parahippocampal areas). In addition, young subjects showed weaker anterior parahippocampal activity during route recognition compared to the old group. In contrast, old compared to young subjects showed less suppressed activity in the left perisylvian region and the anterior cingulate cortex during route encoding. Our findings suggest that agerelated navigational memory deficits might be caused by less effective route encoding based on reduced posterior fusiform/parahippocampal and parietal functionality combined with diminished inhibition of perisylvian and anterior cingulate cortices correlated with less effective suppression of task-irrelevant information. In contrast, age differences in neural correlates of route recognition seem to be rather subtle. Old subjects might show a diminished familiarity signal during route recognition in the anterior parahippocampal region.

(c) 2004 Elsevier Inc. All rights reserved.

Keywords: fMRI; Aging; Human; Medial temporal lobe; Hippocampus; Anterior cingulate; Spatial memory; Declarative memory; Recognition

* Corresponding author. Cognitive Neurology and Memory Research Group, F.C. Donders Center for Cognitive Neuroimaging, University of Nijmegen, P.O. Box 9101, 6500 HB Nijmegen, The Netherlands. Fax: +3124-3610-989.

E-mail address: guillen.fernandez@fcdonders.kun.nl (G. Fernández). Available online on ScienceDirect (www.sciencedirect.com.)

\section{Introduction}

Deficits in spatial and navigational memory are important components of aging-related changes in cognitive abilities (for review, see Kirasic, 2001). It is common that elderly individuals not only avoid unfamiliar routes and places due to self-perceived deficits in navigation (Burns, 1999), they also have measurable deficits in place and route learning as assessed in real and virtual reality environments (Kirasic, 1991; Kirasic et al., 1992; Moffat and Resnick, 2002; Moffat et al., 2001; Wilkniss et al., 1997). Moreover, navigational memory deficits are an important marker of early dementia and thus relevant for early diagnosis (Morris, 1993). Thus, elderly adults encounter more difficulty in learning and remembering new routes in novel environments as compared to younger adults. However, the neural correlates of these age-related differences in route encoding and route recognition are unknown. Moreover, it is unknown whether an encoding or a retrieval deficit causes navigational deficits in old age.

In young subjects, several imaging studies have identified brain structures involved in the encoding of new and recognition of familiar environments (for review, see Burgess et al., 2002). Encoding is consistently accompanied by activation of the dorsal visual pathway reaching the parietal lobe and the ventral visual pathway extending into the medial temporal lobe (MTL). The effectiveness of navigational encoding seems to be positively correlated with inferior and medial temporal activity (Aguirre and D'Esposito, 1997; Aguirre et al., 1996; Hartley et al., 2003; Iaria et al., 2003; Maguire et al., 1998a,b). The general relation between temporal activity and effective encoding is also well supported by studies using the subsequent memory effect, which show greater posterior fusiform/parahippocampal activity for later remembered as compared to later forgotten pictures depicting large-scale spatial layouts (Brewer et al., 1998; Kirchhoff et al., 2000, Weis et al., 2004).

There is considerable overlap in brain activation observed during encoding and retrieval of navigational information. Nevertheless, recognition of learned spatial environments in a route recognition task is often accompanied by more prefrontal activa- 
tions compared to encoding, including activations of the anterior cingulate cortex as well as the pre- and supplementary motor cortices (Burgess et al., 2002).

Although no functional neuroimaging study has yet investigated the neural correlates of age-related deficits in navigational memory, there are several studies that tackle age-related declarative memory deficits in general. The most consistent findings reported in these studies include a reduced encoding-related inferior and medial temporal activity in older as compared to younger subjects (e.g., Daselaar et al., 2003; Grady et al., 1995;Morcom et al., 2003; Schiavetto et al., 2002). In addition, older subjects appear to recruit additionally other brain regions, predominately in the prefrontal cortex. The recruitment of frontal regions together with the relatively diminished responses observed in the temporal lobe and other posterior regions, including the parietal cortex, is sometimes called the posterior-anterior shift (Grady et al., 2003). It has been suggested that with increasing age additional cognitive resources involving executive and organizational functions are utilized instead or in complement to the perceptually based processes engaged by younger subjects. The prefrontal activations in older subjects are often less asymmetric than in young subjects, leading Cabeza (2002) to formulate the so-called HAROLD model (Hemispheric Asymmetry Reduction in Older adults). Such reductions in asymmetry have most consistently been found in high performing older adults (Cabeza et al., 2002). Therefore, the recruitment of the homologue prefrontal region in the contralateral hemisphere has been regarded as a mechanism for compensating age-related deficits in other brain regions including the temporal lobe (Cabeza et al., 2002; Daselaar et al., 2003; Dolcos et al., 2002; Grady and Craik, 2000; Logan et al., 2002). In contrast, in some circumstances, under-recruitment of frontal regions has also been observed in elderly, perhaps indicating that elderly might be less likely to self-initiate the most effective strategy for solving a given task (Cabeza et al., 1997; Grady et al., 1995; Logan et al., 2002).

Summing up the current status, older adults often show a navigational memory deficit, the neural correlates of route encoding and recognition are well studied in young subjects, and studies comparing brain activity related to mnemonic operations between younger and older adults have found consistent differences. However, the neural correlates of age-related deficits in navigational memory are, to our knowledge, yet unstudied. To tackle this issue, we investigated 20 elderly and 20 young healthy subjects by fMRI while they performed a virtual reality spatial memory task including route encoding and route recognition conditions.

\section{Materials and methods}

\section{Participants}

Forty healthy volunteers participated in the study (20 young subjects, 10 female; mean age $=23$ years, $\mathrm{SD}=2.8$, range $18-$ 29; 20 old subjects, 10 female; mean age $=63$ years, $\mathrm{SD}=7.2$, range 53-78). All but two young and two old subjects were right-handed as indexed by an Edinburgh handedness index of $\geq 90$ (Oldfield, 1971). The mean number of years of formal education was $16(\mathrm{SD}=2.0)$ for old and $16(\mathrm{SD}=0.4)$ for young subjects. Dutch was the first language in all subjects. All subjects were high functioning, mostly university educated, autonomous community dwellers. The older subjects, while mostly retired, were all active in cultural pursuits, continuing education or with responsibilities in various associations. All subjects were prescreened and none of them used medication regularly, had a history of drug abuse, head trauma, or a medical condition that could affect cerebral blood flow (e.g., high blood pressure, diabetes, thyroid dysfunction). All subjects had normal or corrected-to-normal vision. The structural MRI investigations (cf. below) did not show any evidence for anatomical abnormalities atypical for the age. All subjects gave written informed consent according to the Declaration of Helsinki and the local medical ethics committee approved the study.

\section{Stimulus material}

We constructed 16 video sequences of ground-level first-person indoor routes through virtual environments each showing a different furnished home and lasting $31 \mathrm{~s}$ using Traumhaus Designer 4.0 software (http://www.databecker.de). The homes were approximately of the same size and similar topology, that is, they contained the same number of rooms, furniture, and other items of daily life. Fourteen sequences were used for the actual fMRI experiment and two sequences for the initial, prescan training session. Each video sequence depicts a fixed route through the different rooms of the homes and included five decision points (i.e., intersections). Two arrowheads, indicating left, right, or straight ahead, appeared at every decision point for $2.5 \mathrm{~s}$ accompanied by a freeze of the video sequence for $2 \mathrm{~s}$. In the route encoding condition, one arrowhead was yellow (predicting the direction where the "travel" will go) and the other red. During the route recognition condition, both arrowheads were red. The interval between each decision point lasted $3.5 \mathrm{~s}$. For the control task, one additional virtual environment was constructed depicting an empty, straight hallway. Here, the video sequence showed the same straight 'walk' and two arrowheads at the end of the hallway (one in yellow and one in red) for five times. The timing of this control video sequence was identical to the other sequences described.

\section{Experimental procedure}

The experiment included four conditions: route encoding, visuomotor control, rest, and route recognition. Each conditions or cycle started with a route encoding condition and ended with a route recognition condition, with the order of the control and rest condition randomly changing over cycles. Before going into the scanner, subjects practiced the task in two cycles with virtual homes not used during the experiment. In the scanner, video sequences were presented by a computer using ERTS software (http://www.erts.de) for stimulus presentation and response recording. Stimuli were back-projected via an LCD-projector onto a translucent screen, which subjects viewed through a mirror mounted at the head coil. Subjects responded with an optical button device held in their dominant hand, and a computer interfaced with the optical switch recorded these responses. Altogether, the experiment consisted of 14 cycles, separated into two runs of seven cycles each. Across subjects, we used two versions of the experiment differing in the order of cycles only. The subject's head was immobilized using a vacuum cushion to reduce motion artifacts. 
Route encoding

While the subjects viewed a video sequence of a virtual home, they were instructed to remember the directions taken at each of the five decision points (left, right, straight ahead) and to press the respective button on the button-box to confirm the direction indicated by the yellow arrowhead and subsequently taken by the video sequence. Each cycle started by indicating to the subject that a new house had to be learned.

\section{Visuomotor control}

Subjects 'traveled' repeatedly along the same empty hallway. When they saw the yellow and the red arrowhead at the end of the hallway, they were instructed to press the button assigned to the direction indicated by the yellow arrowhead.
Rest

During the rest period, the display showed a white, central fixation cross on a black background and no response was required. Subjects were instructed to fixate and concentrate on scanner noise.

\section{Route recognition}

Subjects saw the same video sequence shown previously during the learning condition of the same cycle. They were instructed to indicate by appropriate button-press as accurate as possible the correct of the two alternative directions indicated by two red arrowheads at each decision point. If the subject made an incorrect response, the video went on with the predetermined sequence.

\section{Route encoding versus visuo-motor control: Young subjects}
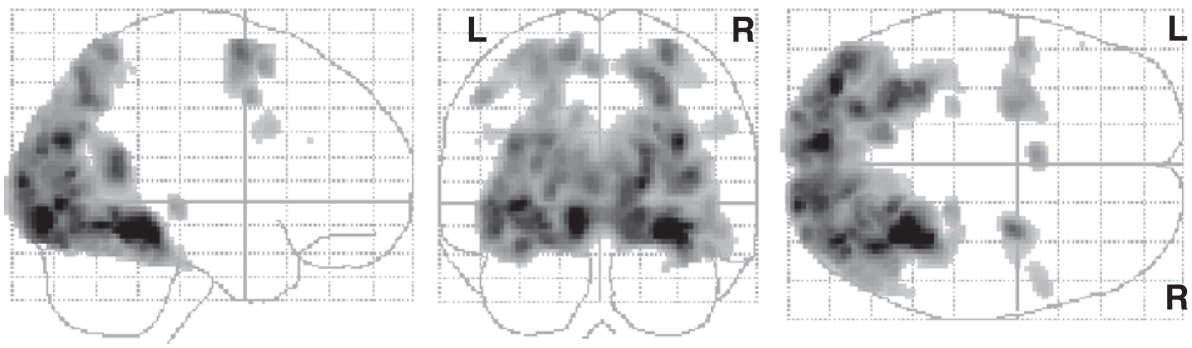

Route encoding versus visuo-motor control: Old subjects
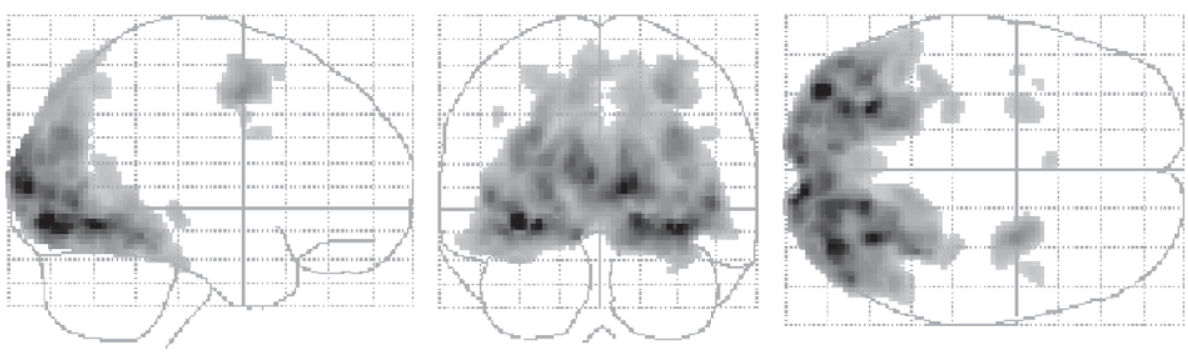

Route recognition versus visuo-motor control: Young subjects
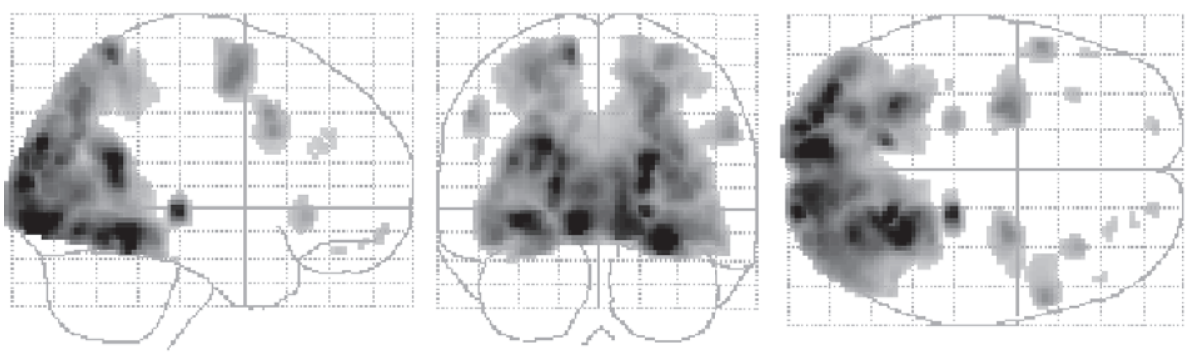

Route recognition versus visuo-motor control: Old subjects
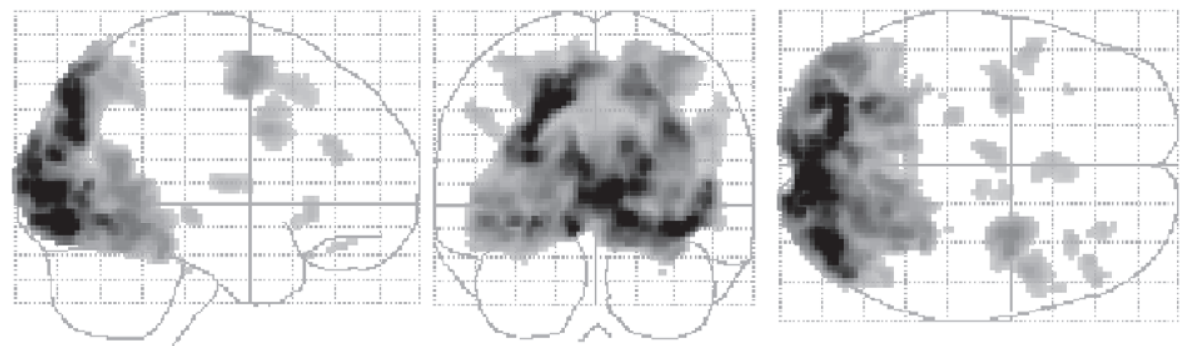

Fig. 1. Brain regions that show greater activity in route encoding than control and route recognition than control displayed separately for old and young subjects. Images here and in the following are thresholded at $P=0.001 ; \mathrm{L}=1$ eft, $\mathrm{R}=$ right. 
While the contrasts between route encoding and visuomotor control as well as route recognition and visuomotor control are assumed to show a comprehensive, less specific picture of brain regions involved in a navigational memory task, the two contrasts between route encoding and recognition are assumed to delineate specifically the formation of navigational memories and their retrieval.

This easy navigational task has three major advantages for the purpose of our study. First, we avoid large performance differences between young and old subjects, enabling us to relate age differences to differences in brain operations and not performance. Second, we avoid free navigation with a joy-stick and thus difficult motor responses that would be much easier for young subjects who often have extensive experiences with computer games. Third, we avoid a "semantic" strategy, in which subjects remember the order of responses left, right, and straight ahead, because such a strategy is much more difficult than a true navigational strategy due to interference by the large number of repetitions of just three possible responses (70 responses).

\section{MRI data acquisition}

During MRI scanning, whole head T2*-weighted EPI-BOLD fMRI data were acquired with a Siemens Sonata 1.5 T MR

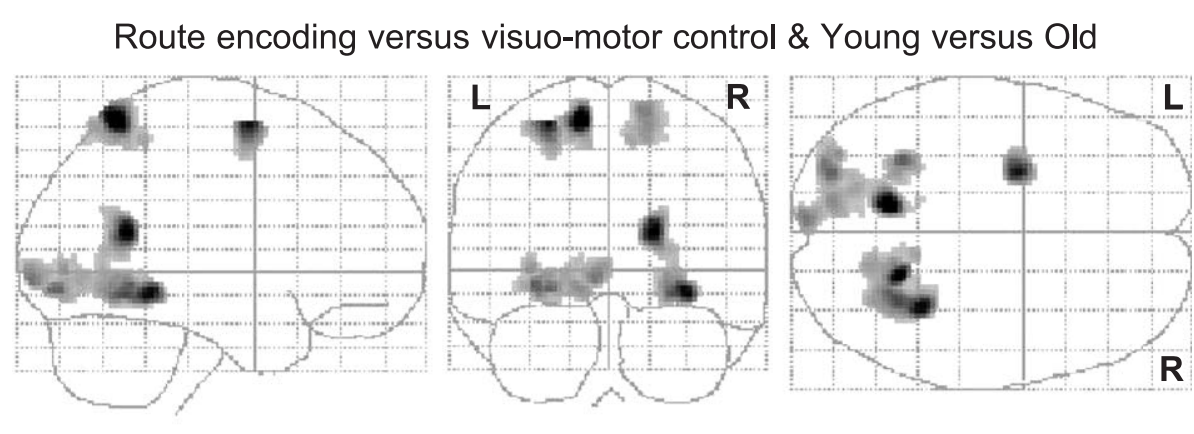

Route encoding versus visuo-motor control \& Old versus Young
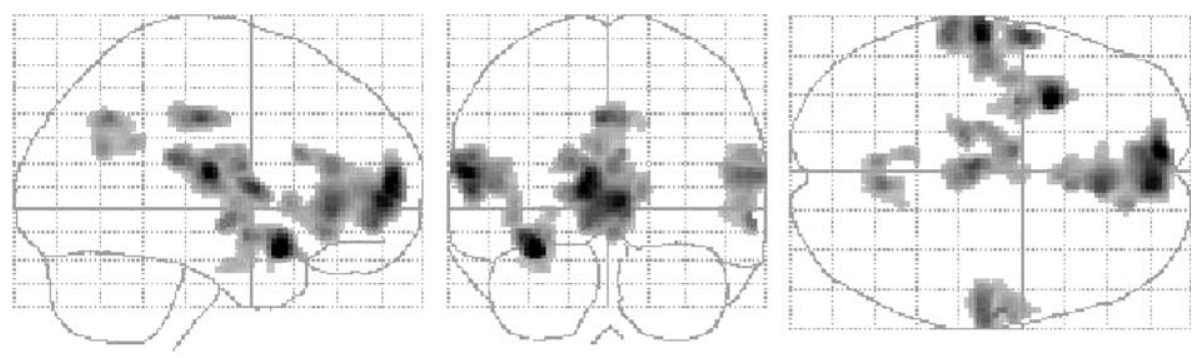

Route recognition versus visuo-motor control \& Young versus Old
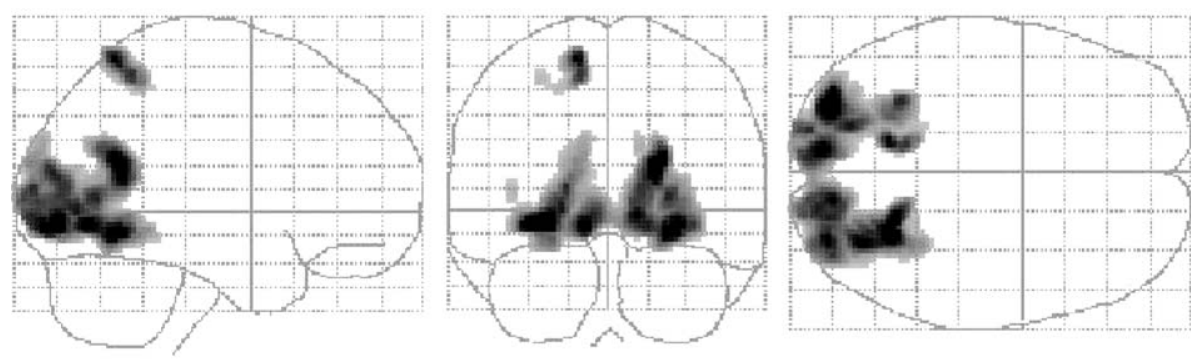

Route recognition versus visuo-motor control \& Old versus Young
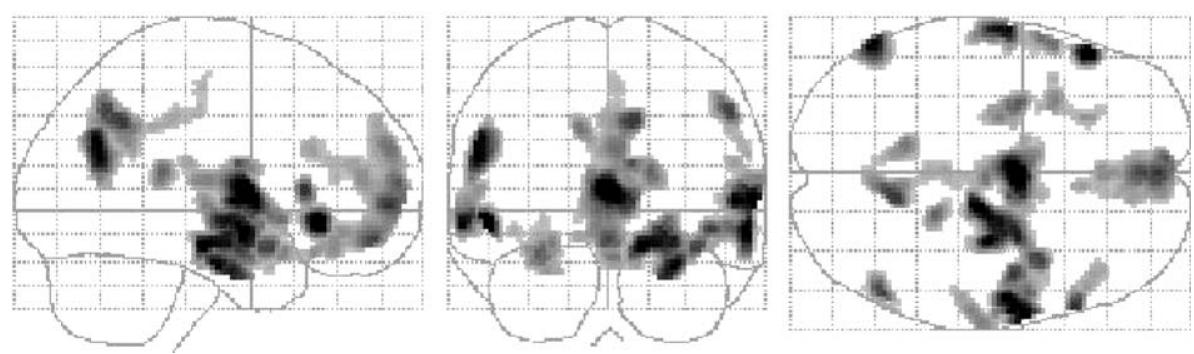

Fig. 2. Brain regions that show relatively greater activity in young subjects as compared to old subjects and vice versa for the contrasts route encoding vs. control and route recognition vs. control. 
scanner using an interleaved slice acquisition EPI sequence (volume $\mathrm{TR}=1.93 \mathrm{~s}, \mathrm{TE}=30 \mathrm{~ms}, 90^{\circ}$ flip-angle, 28 axial slices aligned with the $\mathrm{AC}-\mathrm{PC}$ plane, slice-matrix size $=64 \times$ 64 , slice thickness $=3.5 \mathrm{~mm}$, slice gap $=0.5 \mathrm{~mm}$, FOV $=224$ $\mathrm{mm}$, isotropic voxel size $=3.5 \times 3.5 \times 3.5 \mathrm{~mm}$ ) in a blocked design. For the structural high-resolution MR image volume, a T1-weighted MP-RAGE sequence was used (volume TR $=2250$ $\mathrm{ms}, \mathrm{TE}=3.93 \mathrm{~ms}, 15^{\circ}$ flip-angle, 176 sagittal slices, slice-matrix size $=256 \times 256$, slice thickness $=1 \mathrm{~mm}$, slice gap $=0 \mathrm{~mm}$, voxel-size $=1 \times 1 \times 1 \mathrm{~mm}$ ).

\section{MR image preprocessing and statistical analysis}

Image preprocessing and statistical analysis were performed using the SPM99 software (http:/www.fil.ion.ucl.ac.uk). The functional EPI-BOLD images were realigned and the subjectmean functional MR images were co-registered with the corresponding structural MR images using mutual information optimization. These were subsequently spatially normalized (i.e., the normalization transformations were generated from the structural MR images and applied to the functional MR images) and transformed into a common approximate Talairach space (Talairach and Tournoux, 1988), as defined by the SPM99 MNI T1 template, and finally spatially filtered by convolving the functional image volumes with an isotropic 3D spatial Gaussian filter kernel ( $8 \mathrm{~mm}$ FWHM). The fMRI data were proportionally scaled to account for global effects and analyzed statistically using the general linear model and statistical parametric mapping (Friston et al., 1995). The linear model included convolved explanatory variables (regressors), modeling the encoding, the retrieval, and baseline conditions using boxcar regressors. The explanatory variables were temporally convolved with the canonical hemodynamic response function. In addition, the linear model included the session/subject-effects and a temporal highpass filter to account for various low-frequency effects (e.g., related to different physiological effects such as heart rate and respiration, and slow MR-scanner drifts). To account for temporal autocorrelation, the fMRI data were convolved with a Gaussian (FWHM = 4 s) temporal kernel, and effective degrees of freedom estimated (Worsley and Friston, 1995). In the statistical analysis, for each subject, relevant contrasts corresponding to null-hypotheses were used to generate statistic images, SPM[T]. These were then subjected to a second-level random effects analysis. Results from the random effects analyses were thresholded at $T=3.11$ ( $P=0.001$, uncorrected) and the cluster size was used as the test statistic. Only clusters significant at $P<0.1$ [corrected for multiple non-independent comparisons based on the theory of differentiable 3D stationary random field theory (Adler, 1981; Worsley et al., 1996)] are described. The significant clusters were resolved into peak height of local maxima and only significant local maxima, $P<$ 0.05 [corrected for multiple non-independent comparisons based on the false discovery rate (Genovese et al., 2002)], are reported. The terms of activation and deactivation are used as

\footnotetext{
Note to Table 1:
}

All $P$ values are corrected for multiple nonindependent comparisons. The coordinates of the local maxima refer to the stereotactic space provided by the Montreal Neurological Institute (MNI) brain (Evans et al., 1993).
Table 1

Significant differences of activity in the contrast route encoding vs. visuomotor control

\begin{tabular}{|c|c|c|c|c|}
\hline \multirow{2}{*}{$\frac{\text { Region }}{\text { Brodmann's area }}$} & \multirow{2}{*}{$\frac{\text { Cluster }}{P \text { value }}$} & \multirow[b]{2}{*}{$Z$ score } & \multicolumn{2}{|l|}{ Voxel } \\
\hline & & & $P$ value & {$\left[\begin{array}{lll}x & y & z\end{array}\right]$} \\
\hline \multicolumn{5}{|l|}{ Young vs. old } \\
\hline Right superior parietal region & 0.004 & & & \\
\hline \multirow{3}{*}{ BA 7} & & 4.16 & 0.008 & $16-5666$ \\
\hline & & 3.91 & 0.015 & $16-5856$ \\
\hline & & 3.84 & 0.017 & $14-6660$ \\
\hline Left superior parietal region & 0.003 & & & \\
\hline \multirow[t]{3}{*}{ BA 7} & & 5.88 & $<0.001$ & $-12-5864$ \\
\hline & & 3.22 & 0.050 & $-22-7254$ \\
\hline & & 3.22 & 0.050 & $-12-4658$ \\
\hline Right fusiform region & $<0.001$ & & & \\
\hline BA 37 & & 5.20 & 0.001 & $32-44-8$ \\
\hline BA $19 / 37$ & & 4.68 & 0.002 & $30-54-10$ \\
\hline Left fusiform region & 0.055 & & & \\
\hline BA 37 & & 4.51 & 0.004 & $-32-52-6$ \\
\hline BA $19 / 37$ & & 3.32 & 0.042 & $-22-54-12$ \\
\hline $\begin{array}{l}\text { Right retrosplenial/posterior } \\
\text { cingulate region }\end{array}$ & $<0.001$ & & & \\
\hline BA $23 / 30$ & & 5.28 & 0.001 & $20-5416$ \\
\hline $\begin{array}{l}\text { Right posterior middle frontal } \\
\text { region }\end{array}$ & 0.043 & & & \\
\hline BA 6 & & 5.11 & 0.001 & $-26-262$ \\
\hline Left occipital region & $<0.001$ & & & \\
\hline BA $17 / 18$ & & 4.25 & 0.007 & $-6-94-4$ \\
\hline BA 18 & & 4.05 & 0.011 & $-12-82-8$ \\
\hline BA $18 / 19$ & & 4.47 & 0.004 & $-26-82-8$ \\
\hline
\end{tabular}

Old vs. young

Right superior temporal/ $\quad<0.001$ perisylvian region

BA 22

BA $22 / 40$

4.05

$0.008 \quad 60-8-4$

4.20

$0.007 \quad 64-1614$

Left superior temporal/ $\quad<0.001$

$0.007 \quad 56-1814$

perisylvian region

BA 22/40

Inferior posterior insula/

temporoparietal

operculum

BA $4 / 6$

Medial superior

frontopolar region

Left BA 10

Right BA 10

Right anterior cingulate

region

BA $24 / 32$

Left mid-posterior cingulate region

BA $23 / 31$

Precuneus/posterior cingulate region

Right BA 7

Left BA 31

Left BA 23

Old vs. young

Subcortical areas

Anterior thalamus

Medio-dorsal thalamus

Caudate nucleus

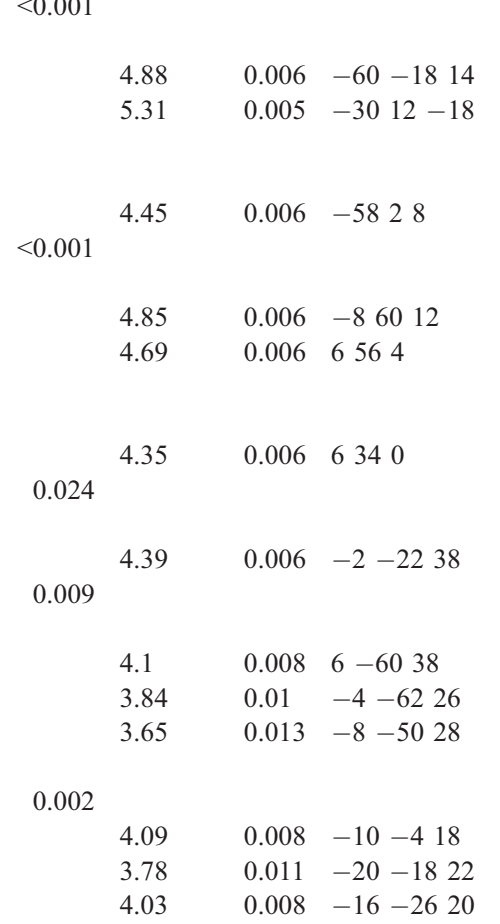


Table 2

Significant differences of activity in the contrast route recognition vs. visuomotor control

\begin{tabular}{|c|c|c|c|c|}
\hline \multirow{2}{*}{$\frac{\text { Region }}{\text { Brodmann's area }}$} & \multirow{2}{*}{$\frac{\text { Cluster }}{P \text { value }}$} & \multirow[b]{2}{*}{$Z$ score } & \multicolumn{2}{|l|}{ Voxel } \\
\hline & & & $P$ value & {$\left[\begin{array}{lll}x & y & z\end{array}\right]$} \\
\hline \multicolumn{5}{|l|}{ Young vs. old } \\
\hline $\begin{array}{l}\text { Bilateral middle/inferior } \\
\text { occipital extending into } \\
\text { the lingual/fusiform } \\
\text { regions }\end{array}$ & $<0.001$ & & & \\
\hline \multirow[t]{2}{*}{ Right BA 17} & & 4.68 & 0.004 & $18-948$ \\
\hline & & 5.33 & $<0.001$ & $12-82-2$ \\
\hline \multirow[t]{2}{*}{ Left BA 17} & & 4.94 & 0.001 & $-6-92-2$ \\
\hline & & 5.02 & $<0.001$ & $16-88-6$ \\
\hline \multirow[t]{3}{*}{ Right BA 18} & & 4.82 & 0.003 & $36-82-6$ \\
\hline & & 4.79 & 0.004 & $12-904$ \\
\hline & & 4.01 & 0.006 & $28-8412$ \\
\hline \multirow[t]{3}{*}{ Left BA 18} & & 5.28 & $<0.001$ & $30-84-6$ \\
\hline & & 5.63 & $<0.001$ & $-10-86-8$ \\
\hline & & 3.70 & 0.010 & $-18-6414$ \\
\hline \multirow[t]{3}{*}{ Right BA 18/19 } & & 4.92 & 0.004 & $26-666$ \\
\hline & & 4.98 & 0.001 & $20-8416$ \\
\hline & & 4.87 & $<0.001$ & $16-8010$ \\
\hline \multirow[t]{2}{*}{ Left BA 18/19 } & & 4.50 & 0.004 & $-24-56-4$ \\
\hline & & 5.06 & $<0.001$ & $-20-740$ \\
\hline Right BA 19 & & 5.46 & $<0.001$ & $30-70-6$ \\
\hline \multirow[t]{2}{*}{ Left BA 19} & & 5.85 & $<0.001$ & $-28-82-6$ \\
\hline & & 4.08 & 0.006 & $-14-9420$ \\
\hline Right BA 19/37 & & 5.80 & $<0.001$ & $26-58-10$ \\
\hline Left BA 19/37 & & 4.49 & 0.004 & $-24-58-12$ \\
\hline Left BA 37 & & 4.97 & 0.001 & $-30-52-8$ \\
\hline \multicolumn{5}{|l|}{$\begin{array}{l}\text { Right retrosplenial/posterior } \\
\text { cingulate region }\end{array}$} \\
\hline BA 23/30 & & 5.67 & $<0.001$ & $22-5620$ \\
\hline $\begin{array}{l}\text { Left superior parietal } \\
\text { region }\end{array}$ & 0.012 & & & \\
\hline \multirow[t]{2}{*}{ BA 7} & & 5.30 & $<0.001$ & $-14-5864$ \\
\hline & & 4.85 & 0.004 & $-12-5058$ \\
\hline
\end{tabular}

Old vs. young

Right anterior temporal/ $\quad<0.001$ medio-temporal region

BA 36

BA 28/34

BA35/28/hippocampus

Anterior hippocampus/ amygdala

BA 22

BA $22 / 38$

BA 22/42

Mid-posterior insula

Perisylvian BA 40

Left anterior medial temporal region

Anterior hippocampus/ amygdala

Hippocampus

Left inferior parietal region

BA 39/40
Table 2 (continued)

\begin{tabular}{|c|c|c|c|c|}
\hline \multirow{2}{*}{$\frac{\text { Region }}{\text { Brodmann's area }}$} & \multirow{2}{*}{$\frac{\text { Cluster }}{P \text { value }}$} & \multirow[b]{2}{*}{$Z$ score } & \multicolumn{2}{|l|}{ Voxel } \\
\hline & & & $P$ value & {$\left[\begin{array}{lll}x & y & z\end{array}\right]$} \\
\hline \multicolumn{5}{|l|}{ Old vs. young } \\
\hline $\begin{array}{l}\text { Left anterior superior/ } \\
\text { middle temporal region }\end{array}$ & 0.001 & & & \\
\hline BA $21 / 22$ & & 4.57 & 0.004 & $-62-6-6$ \\
\hline BA 22 & & 3.80 & 0.008 & $-60-182$ \\
\hline BA 38 & & 3.95 & 0.007 & $-5612-4$ \\
\hline $\begin{array}{l}\text { Fronto-polar/medial } \\
\text { superior frontal/anterior } \\
\text { cingulate region }\end{array}$ & $<0.001$ & & & \\
\hline BA $10 / 32$ & & 4.32 & 0.005 & 0582 \\
\hline BA $11 / 32$ & & 4.21 & 0.005 & $052-12$ \\
\hline Left BA 10 & & 4.11 & 0.005 & -66212 \\
\hline Left BA 47 & & 3.80 & 0.008 & $-3014-18$ \\
\hline $\begin{array}{l}\text { Right middle-inferior } \\
\text { frontal region }\end{array}$ & 0.065 & & & \\
\hline BA 45 & & 4.30 & 0.005 & 582210 \\
\hline \multirow[t]{2}{*}{ BA 47} & & 3.58 & 0.010 & $5028-8$ \\
\hline & & 3.54 & 0.011 & $4430-14$ \\
\hline $\begin{array}{l}\text { Right retrosplenial/posterior } \\
\text { cingulate region }\end{array}$ & 0.001 & & & \\
\hline BA $7 / 31$ & & 4.29 & 0.005 & $10-5638$ \\
\hline BA 31 & & 3.49 & 0.012 & $0-4236$ \\
\hline BA $30 / 31$ & & 3.82 & 0.008 & $6-5232$ \\
\hline Subcortical areas & 0.001 & & & \\
\hline Anterior thalamus & & 5.00 & 0.001 & $0-28$ \\
\hline \multirow[t]{2}{*}{ Right caudate nucleus } & & 3.31 & 0.020 & $16-614$ \\
\hline & & 4.16 & 0.005 & $10-620$ \\
\hline Left globus pallidus & & 3.21 & 0.020 & $-146-4$ \\
\hline Right LGN & & 4.94 & 0.004 & $14-20-14$ \\
\hline \multirow[t]{3}{*}{ Midbrain } & & 3.87 & 0.007 & $-4-6-8$ \\
\hline & & 3.83 & 0.008 & $-40-6$ \\
\hline & & 3.88 & 0.007 & $2-16-20$ \\
\hline
\end{tabular}

Note. All $P$ values are corrected for multiple nonindependent comparisons The coordinates of the local maxima refer to the stereotactic space provided by the Montreal Neurological Institute (MNI) brain (Evans et al., 1993).

synonyms for a relative increase and decrease in BOLD signal, respectively.

\section{Results}

\section{Behavioral results}

The subject performance during route recognition was well above chance level $(50 \%)$ in both groups (young: mean correct $=$ $79.5 \%, \mathrm{SD}=12.0, t_{19}=11.0, P<0.0001$; old: mean correct $=$ $\left.73.3 \%, \mathrm{SD}=16.8, t_{19}=6.2, P<0.0001\right)$. Young subjects performed slightly but significantly better than old subjects $\left(t_{38}=\right.$ $1.3, P<0.05)$

\section{MRI results}

Route encoding vs. visuomotor control condition

In young and old subjects, learning routes through unfamiliar virtual environments significantly activated relative to the visuomotor control condition distributed regions in the parietal, occipital, and inferior temporal lobes (Fig. 1). We also observed additional prefrontal activations, centered on the frontal 
eye fields. Overall, both groups of subjects showed a similar pattern of activation in route encoding vs. the visuomotor control condition. However, by visual inspection, it appears that the activations related to the dorsal and ventral processing streams are stronger in the young as compared to the old subjects (Fig. 1). While the frontal eye field activation appears small and slightly right lateralized in old subjects, the young subjects show a more extended and more symmetric activation of the frontal eye fields in both hemispheres. These apparent differences were confirmed in a second-level statistical comparison of BOLD signal intensity differences in young and old subjects (Fig. 2, Table 1). In this analysis, we revealed that young subjects showed larger BOLD signal intensity differences between the route encoding condition and the visuomotor control condition than old subjects in the bilateral superior parietal (BA 7), bilateral posterior fusiform/parahippocampal area (BA 19/37), left inferior occipital region (BA 17/18), and the left frontal eye field (BA 6). The reverse comparison revealed that the older subjects showed larger BOLD signal intensity differences between the route encoding condition and the visuomotor control condition than young in extended bilateral regions including perisylvian BA 22/40, precuneus/ posterior cingulate (BA 23/31), anterior cingulate (BA 24/32), and medial superior frontal areas (BA 10). However, all of these relative activations in the old subjects represent smaller or missing reductions relative to the baseline provided by the visuomotor control condition.

\section{Route recognition vs. visuomotor control condition}

Similar to route encoding, the occipital-parietal and occipital-temporal areas outlining the dorsal and ventral visual streams were bilaterally activated in the route recognition vs. the visuomotor control condition in both groups of subjects (Fig. 1). The second level comparison young vs. old (Fig. 2, Table 2) revealed that young subjects showed larger BOLD signal intensity differences between the route recognition condition and the visuomotor control condition than old subjects in an inferior occipital (BA 17/18/19) and a superior parietal region (BA 7). In contrast, old subjects showed larger BOLD signal intensity differences between the route recognition condition and the visuomotor control condition than young subjects in the left angular gyrus (BA 39), the left superior temporal region (BA 21, 22, and 38), the anterior and posterior cingulate (BA 32 and 23/31), and the right anterior part of the thalamus as well as medial frontal regions (BA 10, 11, 45, and 47). Again, most of these effects represent smaller reductions relative to the visuomotor control in the old group. However, the old group activated the right middle-inferior frontal gyrus (BA 45), while the young subject showed deactivations in these regions relative to the baseline provided by the visuomotor control condition.

\section{Route encoding vs. route recognition in young vs. old}

Table 3 and Fig. 3 show the results for the contrast route encoding vs. recognition when comparing young with old subjects. As compared to old subjects, young subjects showed larger BOLD signal intensity differences between the route encoding and the route recognition condition in parts of the dorsal and ventral visual streams (left BA 18, 19, 37; right BA $7 / 40$ and 19) as well as the right anterior parahippocampal gyrus. Finally, a small region within the supplementary motor
Table 3

Significant differences of activity in the contrast route encoding vs. route recognition

\begin{tabular}{|c|c|c|c|c|}
\hline \multirow{2}{*}{$\frac{\text { Region }}{\text { Brodmann's area }}$} & \multirow{2}{*}{$\frac{\text { Cluster }}{P \text { value }}$} & \multirow[b]{2}{*}{$Z$ score } & \multicolumn{2}{|l|}{ Voxel } \\
\hline & & & $P$ value & {$\left[\begin{array}{lll}x & y & z\end{array}\right]$} \\
\hline \multicolumn{5}{|l|}{ Young vs. old } \\
\hline $\begin{array}{l}\text { Right inferior temporal- } \\
\text { occipitotemporal region }\end{array}$ & 0.054 & & & \\
\hline BA 34 & & 4.00 & 0.016 & $20-12-12$ \\
\hline BA 28/36 & & 3.67 & 0.023 & $24-14-22$ \\
\hline Posterior BA 36 & & 4.93 & 0.006 & $28-38-18$ \\
\hline BA 37 & & 4.26 & 0.012 & $28-46-8$ \\
\hline BA 18 & & 4.19 & 0.013 & $6-662$ \\
\hline $\begin{array}{l}\text { Left inferior temporal- } \\
\text { occipitotemporal region }\end{array}$ & $<0.001$ & & & \\
\hline \multirow[t]{3}{*}{ BA 19/37 } & & 5.21 & 0.005 & $-48-64-12$ \\
\hline & & 4.23 & 0.012 & $-42-56-16$ \\
\hline & & 3.85 & 0.018 & $-26-54-12$ \\
\hline $\begin{array}{l}\text { Left inferior parietal- } \\
\text { superior occipital region }\end{array}$ & 0.034 & & & \\
\hline BA $19 / 39$ & & 4.65 & 0.007 & $-28-7432$ \\
\hline Right parietal lobe & $<0.001$ & & & \\
\hline BA 7 & & 4.58 & 0.008 & $26-7646$ \\
\hline BA $7 / 40$ & & 3.65 & 0.023 & $32-5650$ \\
\hline BA 19 & & 3.96 & 0.017 & $36-8218$ \\
\hline Medial superior frontal gyrus & 0.095 & & & \\
\hline BA $6 / 8$ & & 4.11 & 0.014 & -21252 \\
\hline \multicolumn{5}{|l|}{ Old vs. young } \\
\hline Perisylvian region & $<0.001$ & & & \\
\hline BA 4/6 & & 3.89 & 0.062 & -44210 \\
\hline BA 22 & & 4.35 & 0.062 & $-60-1616$ \\
\hline BA $40 / 43$ & & 4.34 & 0.062 & $-50-1422$ \\
\hline Anterior cingulate region & $<0.001$ & & & \\
\hline Right BA 24/32 & & 4.07 & 0.062 & 6320 \\
\hline Left BA 24/32 & & 4.26 & 0.062 & -10444 \\
\hline $\begin{array}{l}\text { Right anterior lentiform- } \\
\text { caudate nucleus }\end{array}$ & & 3.98 & 0.062 & $1824-6$ \\
\hline
\end{tabular}

Note. All $P$ values are corrected for multiple nonindependent comparisons. The coordinates of the local maxima refer to the stereotactic space provided by the Montreal Neurological Institute (MNI) brain (Evans et al., 1993).

area was relatively more activated (BA 6/8) in young as compared to old subjects.

Exploring further the basis for these interactions just described, we plotted the parameter estimates in local maxima separately for young and old subjects as well as both contrast: route encoding vs. visuomotor control and route recognition vs. visuomotor control (Fig. 4). Older subjects show indeed weaker encoding-related activity than young subjects in posterior fusiform/parahippocampal and supramarginal regions. In contrast, young subjects exhibit weaker recognition-related activity in the anterior parahippocampal region than old subjects. It is important to note that the activity in this region is on a lower level during both memory conditions than the visuomotor control condition.

\section{Route encoding vs. route recognition in old vs. young}

The results from the contrast route encoding vs. recognition, comparing older vs. younger subjects, can be seen in Table 3 and Fig. 5. Older subjects showed larger BOLD signal intensity differences between the route encoding and the route recogni- 
Route encoding versus route recognition \& Young versus Old
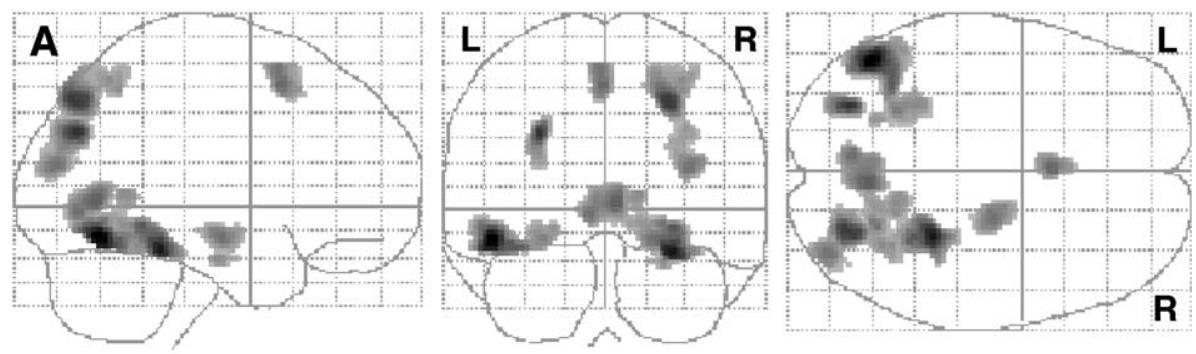

B
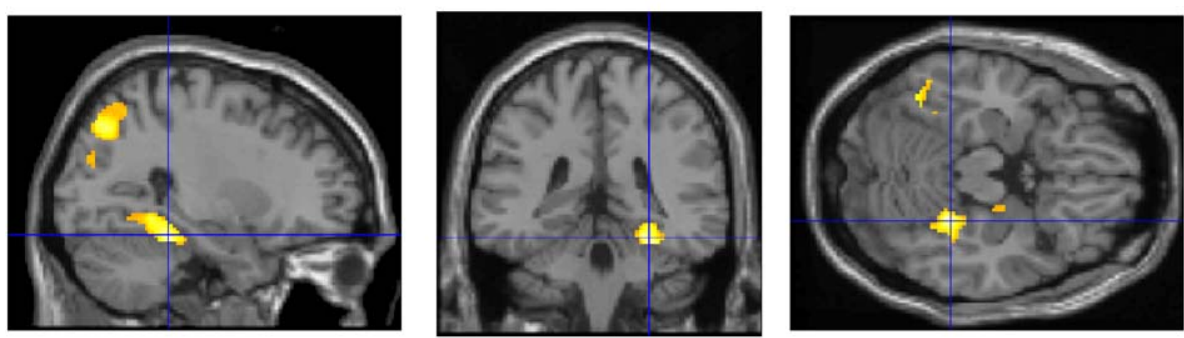

C
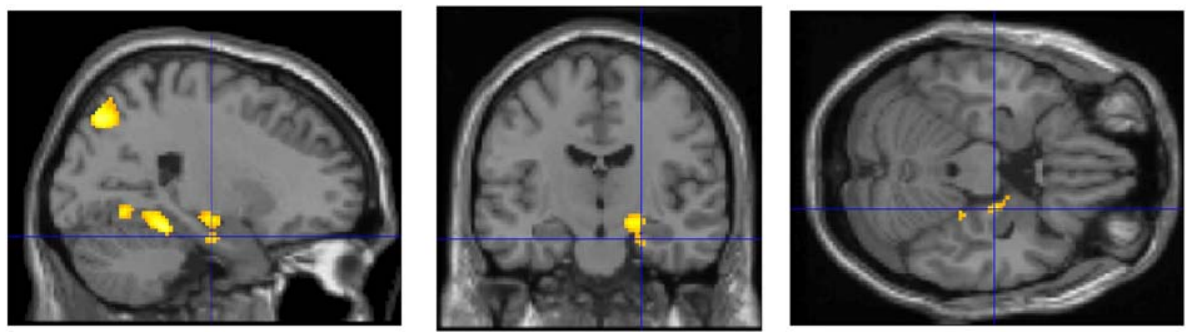

D
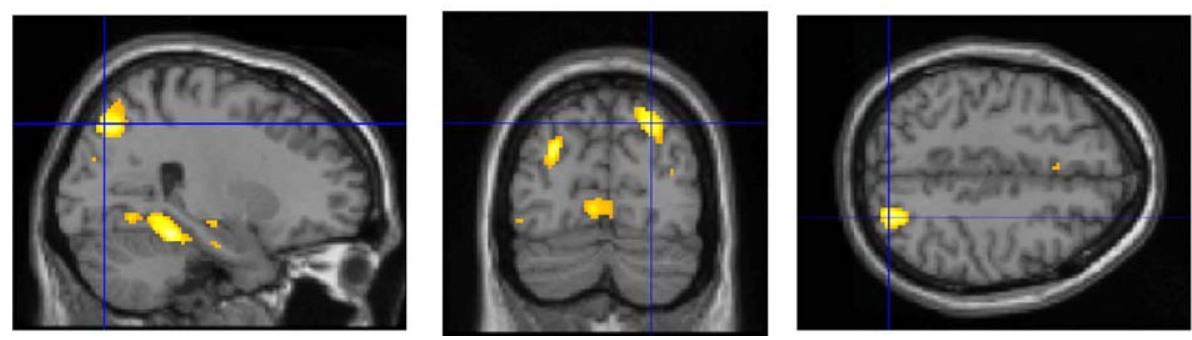

Fig. 3. Brain regions that show relatively greater activity in young than old subjects during route encoding compared to route recognition. While section $\mathrm{A}$ shows a whole brain projection of activations, sections B-D depict the local maxima of the most relevant activations in the right fusiform gyrus (B, BA $36 / 37$; $\left.\left[\begin{array}{ll}x y & z\end{array}\right]=[28-38-18]\right)$, the right anterior parahippocampal gyrus (C, [24-14-22]; BA 28/36) and the right superior parietal region (D, BA 7; [26 - 76 46]).

tion condition than young subjects in the left perisylvian region (including BA 4/6, BA 22 and BA 40/43) and the anterior cingulate (bilateral BA 24/32; Fig. 5C). Again, to explore further the basis for these interactions, we plotted the parameter estimates in local maxima separately for young and old subjects as well as both contrast: route encoding vs. visuomotor control and route recognition and visuomotor control (Fig. 6). Data depicted in Fig. 6 show that young subjects suppress, particularly during route encoding, activity in the superior temporal and anterior cingulate gyri more effectively than old subjects. Hence, these relative activations in old subjects seem to be based on smaller activity reductions and not true increases of activity above the baseline provided by the visuomotor control condition.

\section{Discussion}

The behavioral results indicate that both groups of subjects were able to learn and effectively solve the recognition task. However, there was a small but significant difference in performance between groups. It is likely that this difference is attributable to subtle spatial memory deficits in our sample of older subjects, consistent with previous findings (Kirasic, 1991; Kirasic et al., 1992; Moffat and Resnick, 2002; Moffat et al., 2001;Wilkniss et al., 1997; for review, see Kirasic, 2001).

Route encoding vs. visuomotor control and route recognition vs. visuomotor control activated a neural network known to be involved in spatial navigation and memory (for review, see Burgess et al., 2002). These activations comprise the dorsal and ventral 
Fusiform/parahippocampal area (BA 36/37, 28 - 38-18)
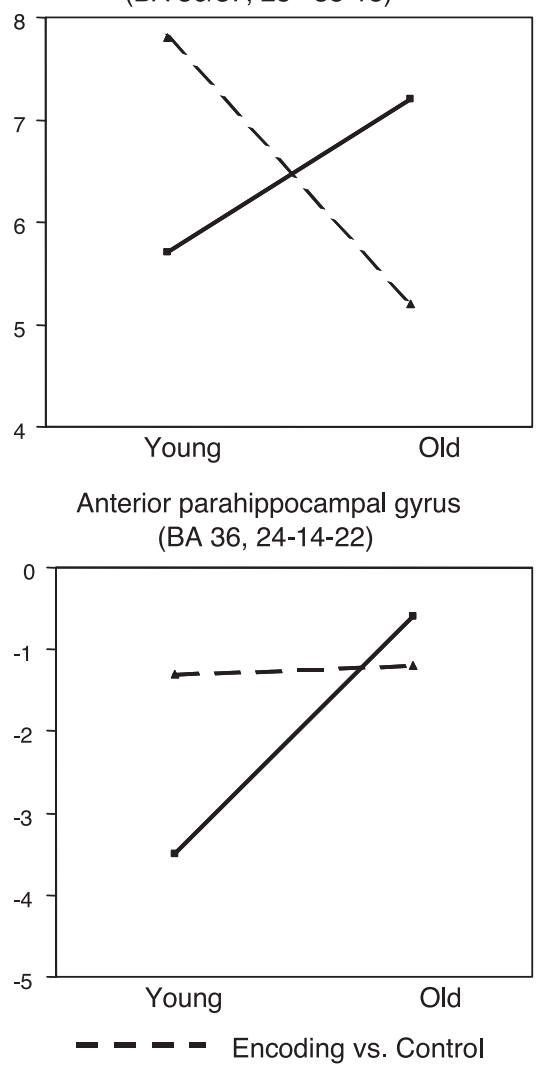

Posterior fusiform gyrus

(BA 18, $6-66$ 2)

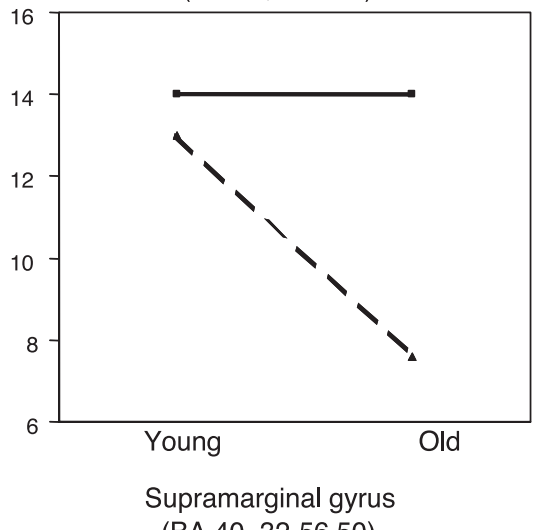

(BA 40, 32-56 50)

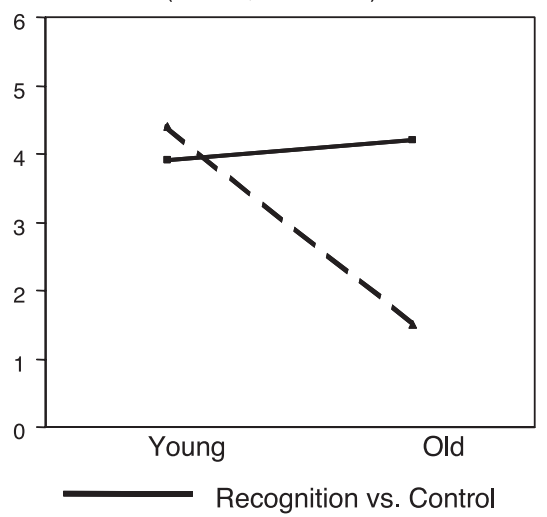

Fig. 4. Parameter estimates of experimental effects (arbitrary units) in local maxima separately plotted for old and young subjects as well as both contrasts: route encoding vs. visuomotor control and route recognition vs. visuomotor control.

visual stream (Mishkin et al., 1983; Ungerleider and Haxby, 1994) and include the frontal eye fields (Corbetta et al., 2002). Our behavioral and imaging findings indicate that the task used in the present study is well suited to investigate the neural correlates of navigational memory deficits in old age.

During encoding, old subjects show as compared to young subjects diminished posterior fusiform/parahippocampal and parietal activity (Figs. 3 and 4). It has been suggested that this area supports memory formation of complex visual stimuli with a spatial layout (Brewer et al., 1998; Kirchhoff et al., 2000; Weis et al., 2004) and geometric analysis of the local environment (Epstein and Kanwisher, 1998). Furthermore, single-cell recordings in humans indicate that landmark information is stored in the parahippocampal cortex (Ekstrom et al., 2003), which covers the posterior half of the parahippocampal gyrus and the medial bank of the fusiform gyrus (Amaral and Insausti, 1990). Also, the parietal area is known to be critically involved in declarative memory formation for visuospatial information (Kirchhoff et al., 2000; Weis et al., 2004). Hence, old subjects seem to exhibit a route-encoding deficit based on reduced functionality of posterior fusiform/parahippocampal and parietal areas. This finding is in accordance with prior functional imaging studies investigating the neural correlates of age differences in memory performance using non-spatial stimuli and underlines the existence of critical age differences in memory formation (e.g., Daselaar et al., 2003; Grady et al., 1995; Morcom et al., 2003; Schiavetto et al., 2002).
The reduced route recognition-related activity in the anterior parahippocampal region of young subjects is more difficult to interpret because this region seems to be less activated during both memory conditions than the visuomotor control condition. Hence, it is questionable whether this region was contributing to memory performance in the present task. Moreover, there is an ongoing discussion about the precise role of the anterior parahippocampal region in declarative memory (Schacter and Wagner, 1999). At least, it has been shown that this region plays a critical role in the formation of new declarative memories with an activity increase (Fernández et al., 1999, 2002; Grasby et al., 1993; Otten et al., 2001; Petersson et al., 1999a; Strange et al., 2002; Tulving et al., 1999; Weis et al., 2004) and in recognition based on familiarity with an activity decrease (Brown and Aggleton, 2001; Henson et al., 2003). Thus, one might speculate that the reduced recognitionrelated activity in the anterior parahippocampal gyrus in young subjects (Fig. 4) is a correlate of a familiarity signal during route recognition, which is weaker or even not existing in old subjects. This speculation seems to contradict the often-replicated behavioral finding that older adults show generally no deficit in familiaritybased recognition (e.g., Clarys et al., 2002; Mantyla, 1993; Parkin and Walter, 1992; Rabinowitz, 1984). However, healthy old adults with reduced medial temporal lobe functionality also show a reduced recognition performance, when recognition judgments were based on a feeling of familiarity (Davidson and Glisky, 2002). Thus, the missing anterior parahippocampal activity de- 


\section{Route encoding versus route recognition \& Old versus Young}
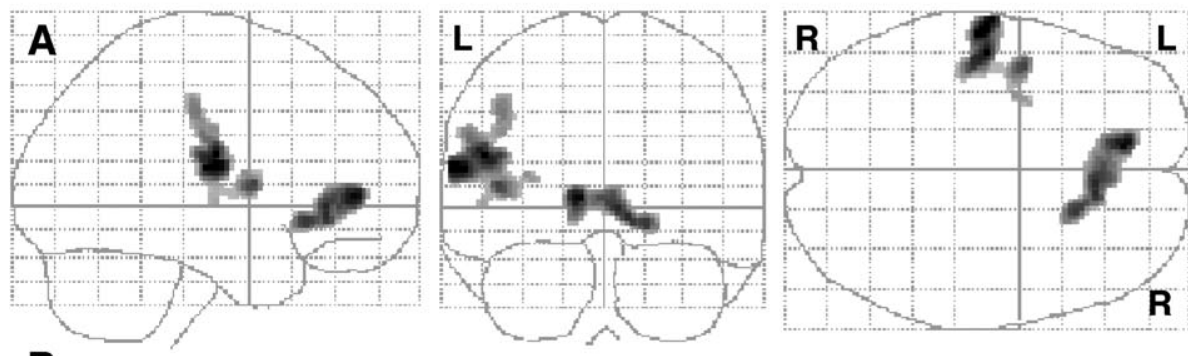

B
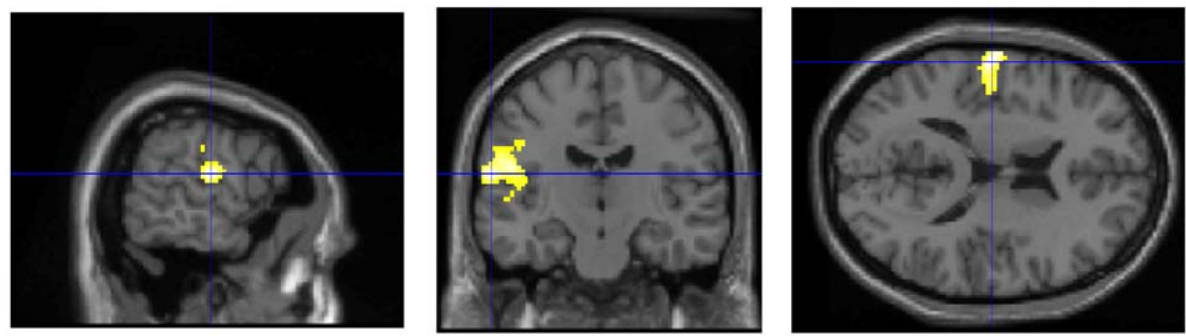

C
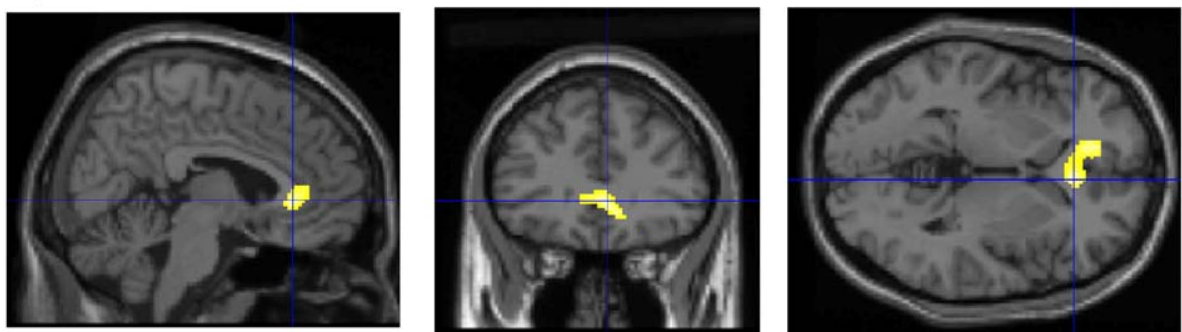

Fig. 5. Brain regions that show relatively greater activity in old than young subjects during route encoding compared to route recognition. While section A shows a whole brain projection of activations, sections $\mathrm{B}$ and $\mathrm{C}$ depict the local maxima of the most relevant activations in the left perisylvian region (B, BA $\left.22 ;\left[\begin{array}{lll}-60 & -16 & 16\end{array}\right]\right)$ and the anterior cingulate cortex (C, BA 24/32; [6 320$]$ ).

crease during route recognition in old subjects might indeed indicate an abolished familiarity signal.

Another age difference in brain activation found during route encoding is the diminished perisylvian deactivation in old subjects (Figs. 5B and 6). This effect might be related to a deficit in suppressing irrelevant input like scanner noise in old age. Several studies investigating the neural correlates of attentional modulation of visual processing tasks found that task-irrelevant processing needs to be suppressed by deactivation of, for instance, the auditory cortex (Ghatan et al., 1998; Gisselgård et al., 2003; Petersson et al., 1999b; Shulman et al., 1997). Also, the relatively stronger activation of the anterior cingulate cortex in old subjects
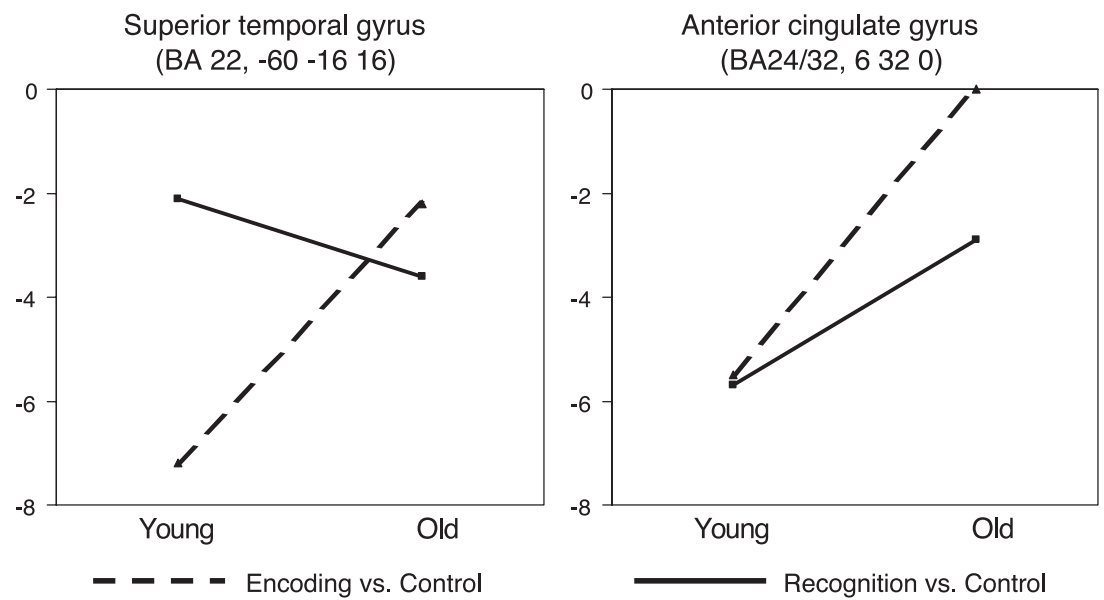

Fig. 6. Parameter estimates of experimental effects (arbitrary units) in local maxima separately plotted for old and young subjects as well as both contrasts: route encoding vs. visuomotor control and route recognition vs. visuomotor control. 
as compared to young (Figs. 5C and 6) can be explained by a failure to suppress or inhibit irrelevant, particularly internal information (Gusnard et al., 2001). Young subjects seemed to be able to suppress activity in these regions during both memory conditions, but old subjects seem to be less effective in doing so, particularly during route encoding. Thus, old subjects might have a relative difficulty in focusing their attention to the relevant input and disregarding the irrelevant aspects of the sensory input or internal information. In other words, the old group may not be able to optimize their processing resources for the task at hand.

In conclusion, the old subjects in the present study showed a subtle navigational memory deficit. Causes of this impairment appear to be related to deficits in spatial memory formation and less effective attentional mechanisms during route encoding. It seems that elderly subjects encode navigational information less effective than young subjects, likely associated with reduced involvement of the dorsal and ventral visual streams extending into the posterior fusiform/parahippocampal area. In addition, older subjects may be less effective during route encoding in suppressing irrelevant information by attentional mechanisms as indicated by less suppressed activity in perisylvian and anterior cingulate cortices. In contrast, age differences in neural correlates of route recognition seem to be rather subtle. We found in old subjects an indication for an anterior parahippocampal dysfunction that might be explained by a diminished familiarity signal during route recognition.

\section{Acknowledgment}

We thank Paul Gaalman for professional technical assistance in data acquisition.

\section{References}

Adler, R.J., 1981. The Geometry of Random Fields. Wiley, New York.

Aguirre, G.K., D’Esposito, M., 1997. Environmental knowledge is subserved by separable dorsal/ventral neural areas. J. Neurosci. 17, $2512-2518$

Aguirre, G.K., Detre, J.A., Alsop, D.C., D’Esposito, M., 1996. The parahippocampus subserves topographical learning in man. Cereb. Cortex 6 , $823-829$

Amaral, D.G., Insausti, R., 1990. Hippocampal formation. In: Paxinos, G. (Ed.), The Human Nervous System. Academic Press, San Diego, pp. $711-755$.

Brewer, J.B., Zhao, Z., Desmond, J.E., Glover, G.H., Gabrieli, J.D., 1998. Making memories: brain activity that predicts how well visual experience will be remembered. Science 281, 1185-1187.

Brown, M.W., Aggleton, J.P., 2001. Recognition memory: what are the roles of the perirhinal cortex and hippocampus? Nat. Rev. Neurosci. 2, 51-61.

Burgess, N., Maguire, E.A., O’Keefe, J., 2002. The human hippocampus and spatial and episodic memory. Neuron 35, 625-641.

Burns, P.C., 1999. Navigation and the mobility of older drivers. J. Gerontol. B Psychol. Sci. Soc. Sci. 54, S49-S55.

Cabeza, R., 2002. Hemispheric asymmetry reduction in older adults: the HAROLD model. Psychol. Aging 17, 85-100.

Cabeza, R., McIntosh, A.R., Tulving, E., Nyberg, L., Grady, C.L., 1997. Age-related differences in effective neural connectivity during encoding and recall. NeuroReport 8, 3479-3483.

Cabeza, R., Anderson, N.D., Locantore, J.K., McIntosh, A.R., 2002. Aging gracefully: compensatory brain activity in high-performing older adults. NeuroImage 17, 1394-1402.
Clarys, D., Isingrini, M., Gana, K., 2002. Mediators of age-related differences in recollective experience in recognition memory. Acta Psychol. 109, 315-329.

Corbetta, M., Kincade, J.M., Shulman, G.L., 2002. Neural systems for visual orienting and their relationships to spatial working memory. J. Cogn. Neurosci. 14, 508-523.

Daselaar, S.M., Veltman, D.J., Rombouts, S.A.R.B., Raaijmakers, J.G.W., Jonker, C., 2003. Neuroanatomical correlates of episodic encoding and retrieval in young and elderly subjects. Brain 126, 43-56.

Davidson, P.S., Glisky, E.L., 2002. Neuropsychological correlates of recollection and familiarity in normal aging. Cogn. Affect. Behav. Neurosci. 2, 174-186.

Dolcos, F., Rice, H.J., Cabeza, R., 2002. Hemispheric asymmetry and aging: right hemisphere decline or asymmetry reduction. Neurosci. Biobehav. Rev. 26, 819-825.

Ekstrom, A.D., Kahana, M.J., Caplan, J.B., Fields, T.A., Isham, E.A., Newman, E.L., Fried, I., 2003. Cellular networks underlying human spatial navigation. Nature 425, 184-188.

Epstein, R., Kanwisher, N., 1998. A cortical representation of the local visual environment. Nature 392, 598-601.

Evans, A.C., Collins, D.L., Mills, S.R., Brown, E.D., Kelly, R.L., Peters, T.M., 1993. 3D statistical neuroanatomical models from 305 MRI volumes. Proc IEEE 3, 1813-1817.

Fernández, G., Effern, A., Grunwald, T., Pezer, N., Lehnertz, K., Dümpelmann, M., et al., 1999. Real-time tracking of memory formation in the human rhinal cortex and hippocampus. Science 285, 1582-1585.

Fernández, G., Klaver, P., Fell, J., Grunwald, T., Elger, C.E., 2002. Human declarative memory formation: segregating rhinal and hippocampal contributions. Hippocampus 12, 514-519.

Friston, K.J., Holmes, A.P., Worsley, K.J., Poline, J.-B., Frackowiak, R.S.J., 1995. Statistical parametric maps in functional imaging: a general linear approach. Hum. Brain Mapp. 2, 189-210.

Genovese, C.L., Lazar, N.A., Nichols, T., 2002. Thresholding of statistical maps in functional neuroimaging using the false discovery rate. NeuroImage 15, 870-878.

Ghatan, P.H., Hsieh, J.C., Petersson, K.M., Stone-Elander, S., Ingvar, M., 1998. Coexistence of attention-based facilitation and inhibition in the human cortex. NeuroImage 7, 23-29.

Gisselgård, J., Petersson, K.M., Baddeley, A., Ingvar, M., 2003. The irrelevant speech effect: a pet study. Neuropsychologia 41, 1899-1911.

Grady, C.L., Craik, F.I., 2000. Changes in memory processing with age. Curr. Opin. Neurobiol. 10, 224-231.

Grady, C.L., McIntosh, A.R., Horwitz, B., Maisog, J.M., Ungerleider, L.G., Mentis, M.J., Pietrini, P., Schapiro, M.B., Haxby, J.V., 1995. Agerelated reductions in human recognition memory due to impaired encoding. Science 269, 218-221.

Grady, C.L., McIntosh, A.R., Craik, F.I., 2003. Age-related differences in the functional connectivity of the hippocampus during memory encoding. Hippocampus 13, 572-586.

Grasby, P.M., Frith, C.D., Friston, K., Frackowiak, R.S., Dolan, R.J., 1993. Activation of the human hippocampal formation during auditory-verbal long-term memory function. Neurosci. Lett. 163, 185-188.

Gusnard, D.A., Akbudak, E., Shulman, G.L., Raichle, M.E., 2001. Medial prefrontal cortex and self-referential mental activity: relation to a default mode of brain function. Proc. Natl. Acad. Sci. U. S. A. 98, $4259-4264$.

Hartley, T., Maguire, E.A., Spiers, H.J., Burgess, N., 2003. The well-worn route and the path less traveled: distinct neural bases of route following and wayfinding in humans. Neuron 37, 877-888.

Henson, R.N., Cansino, S., Herron, J.E., Robb, W.G., Rugg, M.D., 2003. A familiarity signal in human anterior medial temporal cortex? Hippocampus 13, 301-304.

Iaria, G., Petrides, M., Dagher, A., Pike, B., Bohbot, V.D., 2003. Cognitive strategies dependent on the hippocampus and caudate nucleus in human navigation: variability and change with practice. J. Neurosci. 23, 5945-5952.

Kirasic, K.C., 1991. Spatial cognition and behavior in young and elderly 
adults: implications for learning new environments. Psychol. Aging 6, $10-18$.

Kirasic, K.C., 2001. Aging and spatial behavior in the elderly adult. In: Kitchin, R., Freundschun, S. (Eds.), Cognitive Mapping: Past, Present, and Future. Routledge Frontiers of Cognitive Science. Taylor and Francis, London, pp. 166-178.

Kirasic, K.C., Allen, G.L., Haggerty, D., 1992. Age-related differences in adults' macrospatial cognitive processes. Exp. Aging Res. 18, 33-39.

Kirchhoff, B.A., Wagner, A.D., Maril, A., Stern, C.E., 2000. Prefrontaltemporal circuitry for episodic encoding and subsequent memory. J. Neurosci. 20, 6173-6180.

Logan, J.M., Sanders, A.L., Snyder, A.Z., Morris, J.C., Buckner, R.L., 2002. Under-recruitment and nonselective recruitment: dissociable neural mechanisms associated with aging. Neuron 33, 827-840.

Maguire, E.A., Burgess, N., Donnett, J.G., Frackowiak, R.S., Frith, C.D., O'Keefe, J., 1998a. Knowing where and getting there: a human navigation network. Science 280, 921-924.

Maguire, E.A., Frith, C.D., Burgess, N., Donnett, J.G., O'Keefe, J., 1998b. Knowing where things are parahippocampal involvement in encoding object locations in virtual large-scale space. J. Cogn. Neurosci. 10, $61-76$.

Mantyla, T., 1993. Knowing but not remembering: adult age differences in recollective experience. Mem. Cogn. 21, 379-388.

Mishkin, M., Ungerleider, L.G., Macko, K.A., 1983. Object vision and spatial vision: two cortical pathways. Trends Neurosci. 6, 414-417.

Moffat, S.D., Resnick, S.M., 2002. Effects of age on virtual environment place navigation and allocentric cognitive mapping. Behav. Neurosci. 116, 851-859.

Moffat, S.D., Zonderman, A.B., Resnick, S.M., 2001. Age differences in spatial memory in a virtual environment navigation task. Neurobiol. Aging 22, 787-796.

Morcom, A.M., Good, C.D., Frackowiak, R.S.J., Rugg, M.D., 2003. Age effects on the neural correlates of successful memory encoding. Brain 126, 213-229.

Morris, J.C., 1993. The clinical dementia rating (CDR): current version and scoring rules. Neurology 43, 2412-2414.

Oldfield, R.C., 1971. The assessment and analysis of handedness: the Edinburgh inventory. Neuropsychologia 9, 97-113.

Otten, L.J., Henson, R.N., Rugg, M.D., 2001. Depth of processing effects on neural correlates of memory encoding: relationship between findings from across- and within-task comparisons. Brain 124, 399-412.
Parkin, A.J., Walter, B.M., 1992. Recollective experience, normal aging, and frontal dysfunction. Psychol. Aging 7, 290-298.

Petersson, K.M., Reis, A., Castro-Caldas, A., Ingvar, M., 1999a. Effective auditory-verbal encoding activates the left prefrontal and medial temporal lobes: a generalization to illiterate subjects. NeuroImage 10 , $45-54$.

Petersson, K.M., Elfgren, C., Ingvar, M., 1999b. Dynamic changes in the functional anatomy of the human brain during recall of abstract designs related to practice. Neuropsychologia 37, 567-587.

Rabinowitz, J.C., 1984. Aging and recognition failure. J. Gerontol. 39, $65-71$.

Schacter, D.L., Wagner, A.D., 1999. Medial temporal lobe activations in fMRI and PET studies of episodic encoding and retrieval. Hippocampus 9, 7-24.

Schiavetto, A., Köhler, S., Grady, C.L., Winocur, G., Moscovitch, M., 2002. Neural correlates of memory for object identity and object location: effects of aging. Neuropsychologia 40, 1428-1442.

Shulman, G.L., Corbetta, M., Buckner, R.L., Raichle, M.E., Fiez, J.A., Miezin, F.M., et al., 1997. Top-down modulation of early sensory cortex. Cereb. Cortex 7, 193-206.

Strange, B.A., Otten, L.J., Josephs, O., Rugg, M.D., Dolan, R.J., 2002. Dissociable human perirhinal, hippocampal, and parahippocampal roles during verbal encoding. J. Neurosci. 22, 523-528.

Talairach, J., Tournoux, P., 1988. Co-planar Stereotaxic Atlas of the Human Brain. Georg Thieme Verlag, Stuttgart.

Tulving, E., Habib, R., Nyberg, L., Lepage, M., McIntosh, A.R., 1999. Positron emission tomography correlations in and beyond medial temporal lobes. Hippocampus 9, 71-82.

Ungerleider, L.G., Haxby, J.V., 1994. 'What' and 'where' in the human brain. Curr. Opin. Neurobiol. 4, 157-165.

Weis, S., Klaver, P., Reul, J., Elger, C.E., Fernández, G., 2004. Temporal and cerebellar brain regions that support both declarative memory formation and retrieval. Cereb. Cortex 14, 256-267.

Wilkniss, S.M., Jones, M.G., Korol, D.L., Gold, P.E., Manning, C.A., 1997. Age-related differences in an ecologically based study of route learning. Psychol. Aging 12, 372-375.

Worsley, K.J., Friston, K.J., 1995. Analysis of fMRI time-series revisitedagain. NeuroImage 2, 173-181.

Worsley, K.J., Marrett, S., Neelin, P., Vandal, A.C., Friston, K.J., Evans, A.C., 1996. A unified statistical approach for determining significant signals in images of cerebral activation. Hum. Brain Mapp. 4, 58-73. 